\title{
Encapsulated Data Image Data Type
}

National Cancer Institute

\section{Source}

National Cancer Institute. Encapsulated Data Image Data Type. NCI Thesaurus. Code C95650.

A data type comprised of encapsulated data in the form of an image. 